\title{
Reduction of Power in High Frequency Oscillators using Active Elements for Focused Ultrasound Application
}

\author{
Sarita Zutshi Bhan \\ Research Scholar, Dept. of Electronics and \\ Communication Engineering, Lingayas University \\ Faridabad, India
}

\author{
Pragati Kapoor, PhD \\ Dean Academics, Dept. of Electronics and \\ Communication Engineering, Lingayas University, \\ Faridabad
}

\begin{abstract}
The continuous efforts to improve the medical trends for various diseases have given arise to the concept of Focused Ultrasound which is being claimed to be one of the best ways of treating deadly disease like Cancer of different types, Neurological disorders and many more. The introduction of latest trends in electronic world is contributing in its own way to improve the different strategies behind this focused ultrasound technique. This paper shall be discussing the implementation of high frequency oscillators using active element for their application in the transducers used in High Frequency Focused Ultrasound technology.
\end{abstract}

\section{General Terms}

Active Elements, Focused Ultrasound, Oscillators

\section{Keywords}

Focused Ultrasound, Active Element, Transducers, Oscillators.

\section{INTRODUCTION}

The introduction of active elements in the electronic field has brought a huge advancement in the various electronic circuits thus making them more reliable, power efficient and attractive in terms of incorporation of latest demand of customers from every walk of life. This advancement has also been very much useful for the upgradation of technical aspects of biomedical instrumentation.

Therefore latest Active Elements shall be used in place of traditional active elements to compare and verify the results on the basis of different samples recovered after the experimentation processes.

It was in year 1950 when first ultrasound instrument was introduced but similar type of units were made available for limited and experimental purpose by 1960 . The oscillators used for signal generation for driving the transducers used in high frequency focused ultrasound are being implemented using active element - CCCII (Current Controlled Conveyor of Second generation) and the results thus obtained are found more promising as compared to the traditional oscillators.

\section{HISTORY OF FOCUSED}

\section{ULTRASOUND}

From past six decades, the Ultrasound has emerged as widely available and most frequently used electro physical agent used by Physiotherapists. This technology has been intervening for acute and chronic conditions, different types of tissues and anatomic locations as well. In case of Physiotherapy, the areas focused for treatment with ultrasound have been reported as ligament, muscle, tendon, treating mostly the areas of peripheral joints. The therapists have been using two trends of treatment dosages i.e pulsed wave ultrasound at an intensity in the range of 0.51 to $1.5 \mathrm{~W} / \mathrm{cm}^{2}$ and continuous wave ultrasound at a spatial averaged intensity of 1.01 to 2.1 $\mathrm{W} / \mathrm{cm}^{2}$. By this phase, the therapists had been promoting the non-thermal effects of ultrasound. [25]

The introduction of QUS (Quantitative Ultrasound) methods has offered favourable results and has been recognised with appreciating potential by clinicians and researchers. [27]

The myocardial deformation in longitudinal, radial and circumferential direction can be determined by ultrasound machine thus serving as reference tool in detecting the subtle and early damages of heart tissues. [30]

For detection of Prostate Cancer, Conventional transrectal greyscale ultrasound technique is used, though it has been proposed that by using multiparamter ultrasound, the results obtained can be far better. [31]

The most common movement disorder namely Essential Tremor occurs due to rhythmic oscillations of around 8 to 12 $\mathrm{Hz}$ of agonist and antagonist muscle groups.

Recent advances have enabled delivery of high-intensity focused ultrasound through the intact human cranium with magnetic resonance imaging (MRI) guidance. This preliminary study investigates the use of transcranial MRIguided focused ultrasound Thalamotomy for the treatment of essential tremor. Essential tremor, the most common movement disorder, with a prevalence as high as $4 \%$, is characterized by a rhythmic oscillation of agonist and antagonist muscle groups, typically between 8 and $12 \mathrm{~Hz}$. The existing medical therapies though being successful but are not feasible for all patients due to their intolerance towards such medications.

The Table No. 1 depicts the areas where the focused ultrasound is expected to increase the curing rate of patients who get diagnosed with diseases mentioned in this table.

As per records in FUS Foundation in California, this technology is being designed by 10 manufacturers in North America, by 12 manufacturers in Europe and 10 in Asia as shown in Figure No.1.

As per records in FUS Foundation in California, depicted in Figure No.1, it was in around 1950s when this technology was initially used for treatment of pain. In 1960s, the movement disorder like Essential Tremors or Parkinson's disease was started to be treated with this technology. Gradually in 1980s, this technology found its ways to treat diseases like Vertigo and Glaucoma. The 1990s saw a great advancement as the outcome of continual research work in this field and chronic diseases like tumors, breast cancer, liver tumor, Pancreatic tumor, Prostate Cancer, BPH found non-invasive treatment 
procedures using this technology. The 2000s era brought more accomplishments in this field as the brain tumor also found its treatment using this technology. Within past few years, research in this field has just shown wonderful results for treating the diseases like Depression, Alzheimer etc. though these results are yet to be applied on human breed but it has been a great success on animal mammals. [38]

The Table No. 2 depicts the list of manufacturers who are into the manufacturing of equipments related to HIFU across the North America, Europe and Asia. [39]

Table 1. List of Diseases Claimed to be curable by FUS [37]

STATUS BY DISEASE CATEGORY

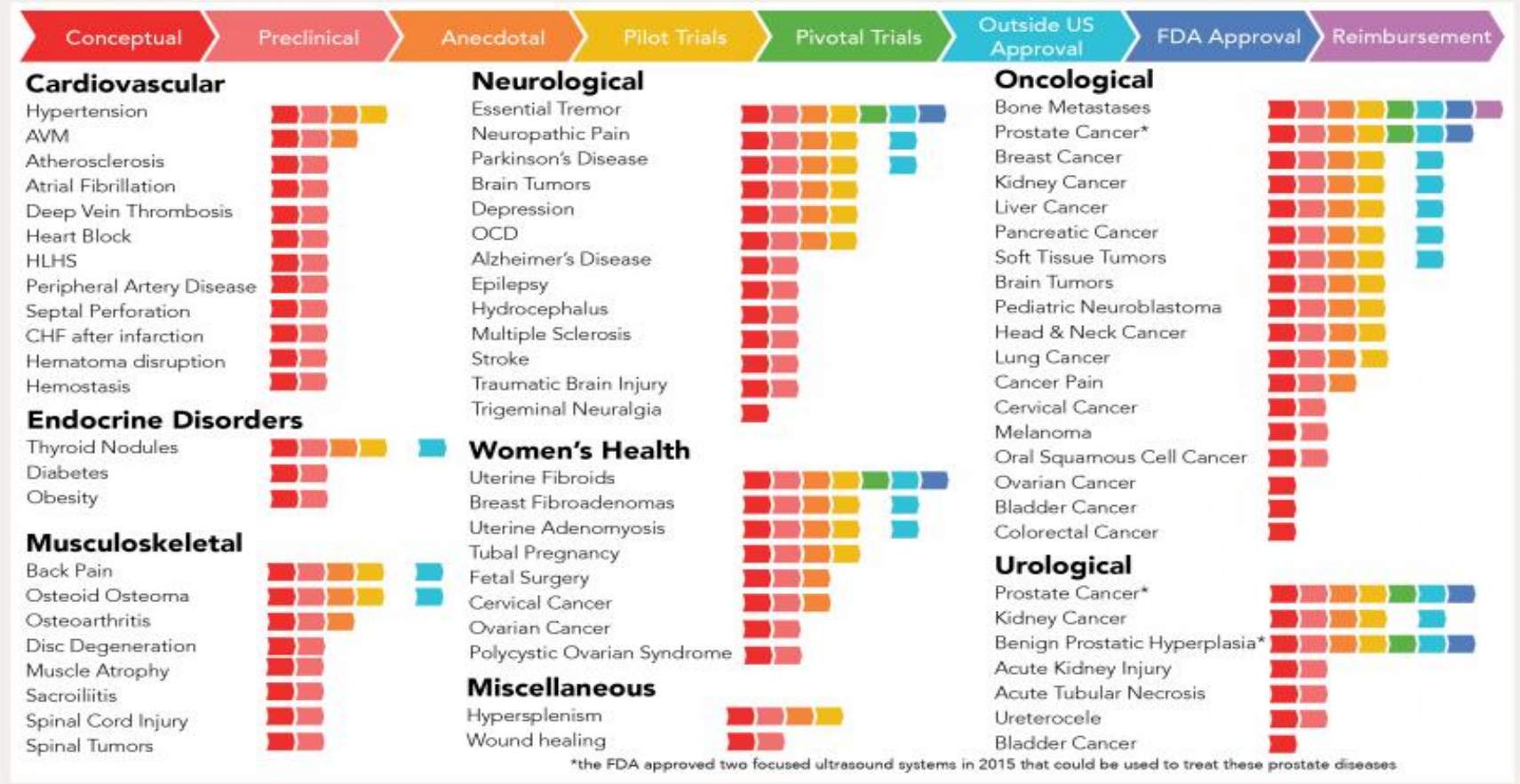

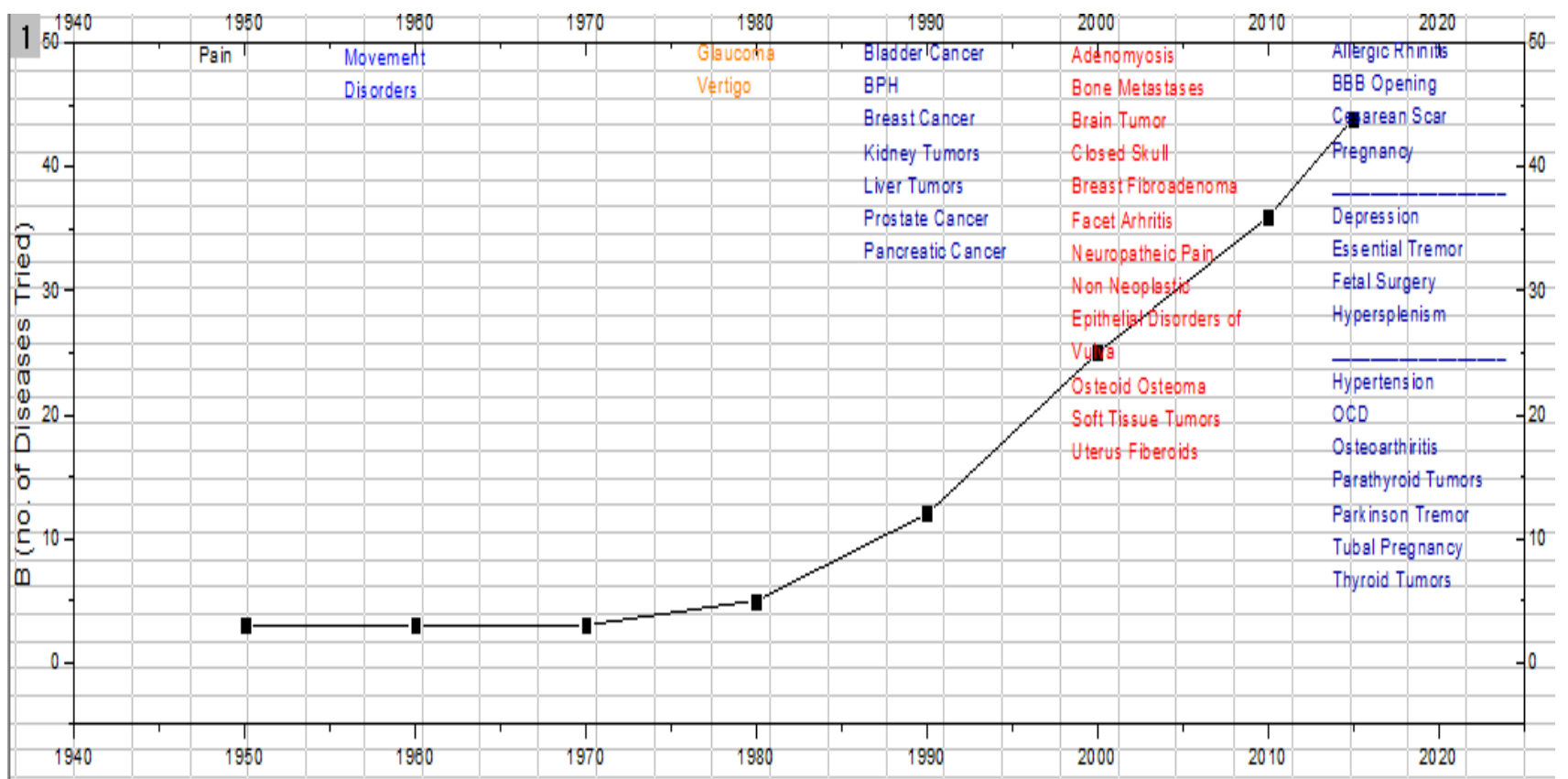

Fig 1: List of diseases cured by HIFU Technique 
Table 2. Manufacturers by Region

\begin{tabular}{|l|l|l|}
\hline \multicolumn{1}{|c|}{ North America } & \multicolumn{1}{|c|}{ Europe } & \multicolumn{1}{c|}{ Asia } \\
\hline BrainSonix Sherman Oaks, California & Acublate London, UK & Alpinion Medical Systems Seoul, Korea \\
\hline FUS Instruments Inc. Toronto, Canada & CarThera Paris, France & $\begin{array}{l}\text { Changjiangyuan Technology Development } \\
\text { Co., LTD Shenyang China }\end{array}$ \\
\hline Histosonics Inc. Ann Arbor, Michigan & EDAP TMS S.A.Vaulx-en-Velin, France & $\begin{array}{l}\text { Chongqing Haifu (HIFU) Medical } \\
\text { Technology Co. LTD Chongqing, China }\end{array}$ \\
\hline $\begin{array}{l}\text { International Cardio Corporation, } \\
\text { Minnetonka, Minnesota }\end{array}$ & EyeTechCare Rillieux-la-Pape, France & EpiSonica Hsichu City, Taiwan \\
\hline Kona Medical Bellevue, Washington & Image Guided Therapy Pessac, France & Mianyang Sonic Electronic Mianyang, China \\
\hline Mirabilis Medica Bothell, Washington & Imasonic Voray-sur-I'Ognon, France & NaviFUS New Taipei City, Taiwan \\
\hline $\begin{array}{l}\text { Profound Medical Inc. Toronto, } \\
\text { Canada }\end{array}$ & InSightec LTD Tirat Carmel, Israel & Shanghai A\&S Co. LTD Shanghai, China \\
\hline $\begin{array}{l}\text { SonaCare Medical, Charlotte, North } \\
\text { Carolina }\end{array}$ & Medsonic LTD Limassol, Cyprus & $\begin{array}{l}\text { Shenzhen PRO-HIFU Medical Tech. Co. Ltd. } \\
\text { Shenzhen, China }\end{array}$ \\
\hline
\end{tabular}

\section{ACTIVE ELEMENTS}

In 1968, Sedra and Smith emerged with the concept of Current Conveyor which started the trend of Current Mode Active Elements as replacement for Operational Amplifiers to overcome its limitations in bandwidth and slew rate. This Current Conveyor concept was soon discovered to be very useful and efficient concept which gradually led to the invention of numerous other active building blocks. In 1996 CMOS Differential Difference Operational Floating Amplifier was introduced which was found useful for developing MOSFET - C current mode filters. This building block remains unaffected even if the threshold voltage varies due to body effect and this property makes it a versatile device to be implemented as integrated circuit. [5]

In 2011 CMOS realisation of VDTA (Voltage Differencing Transconductance Amplifier) was done and it was observed that this building block is functional for transconductance and voltage mode operations. The implementation of VDTAs for filter realisations also avoided the disadvantages due to resistors [7].

In 2012 CMOS realisation of VDBA (Voltage Differencing Buffered Amplifier) and its implementation for Biquad Filter was proposed which was somehow not the choice of designers due to its limitation of using more active components whereas CDBA (Current Differencing Buffered Amplifier) involved less active components and was hence modified further for more precise and efficient results. [4]

In December 2008, Dalibor Biolek, Raj Senani, Viera Biolkova and Zdeněk Kolka again reviewed the existing Active Building Blocks and came up with their limitations to be used for linear applications. They emphasized strongly to modify the internal architecture of existing active elements on the basis of various issues related to various applications implemented by these building blocks. [1]

The continuous efforts for modifying the existing active building blocks and creating new ones also started becoming trend which paved way for modification of various applications of such active building blocks. In December 2012, Bi quad filter was developed using FDCCII (Fully
Differential Current Conveyor) which involved less number of active components as compared to its previous version. [18]

The trend of improving the analog circuits using these active building blocks is still on its move. In August 2015, electronically controlled voltage mode sinusoidal oscillator was implemented using just two VDTAs, two grounded capacitor and single resistor and pure sinusoidal waveforms were generated with good satisfaction level. [15]

Soon after in October 2015, second order voltage mode Quadrature Oscillator was designed using Voltage Current Controlled Conveyor Transconductance Amplifier, two grounded resistors and two grounded capacitors which made it suitable for monolithic circuit implementation. [17]

\section{OSCILLATORS}

\subsection{Introduction of Oscillators}

As we know, the oscillators are self-driven electronic circuits which are capable of generation of oscillations without any input. They employ the positive feedback along with the amplification process so as to generate sustained oscillations as far as possible. The frequency of these oscillations can be produced in various ranges depending upon the different components involved in designing of oscillator.

\subsection{Types of Oscillators}

Oscillators are classified on the basis of type of signal that they produce as:

1. Sine Wave Oscillators which produce a sine wave output.

2. Relaxation Oscillators and Astable Multivibrators which produce Square waves and rectangular pulses.

3. Sweep Oscillators which produce saw tooth waves.

These sine wave oscillators are further classified by frequency, or the type of frequency control they use RF (radio frequency) oscillators working at frequencies above about 30 to $50 \mathrm{kHz}$ use LC (inductors and capacitors) or Crystals to control their frequency. LF (low frequency) oscillators are generally used for generating frequencies below about $30 \mathrm{kHz}$ and are usually 
$\mathrm{RC}$ oscillators, as they use resistors and capacitors to control their frequency.

Square wave oscillators such as relaxation and astable oscillators may be used at any frequency from less than $1 \mathrm{~Hz}$ up to several $\mathrm{GHz}$ and are very often implemented in integrated circuit form.

Sweep oscillators are generally used in television circuitries.

The different commercially available existing oscillators are named as RC oscillators, LC oscillators, Crystal Oscillators, Wein Bridge Oscillators whose comparative analysis is discussed in next section.

\section{RESULTS AND COMPARATIVE ANALYSIS OF OSCILLATORS}

The different oscillators were designed using National Instrument's Multisim software of version 12.0 as shown in figures below:

\subsection{Collpits Oscillator Implementation}

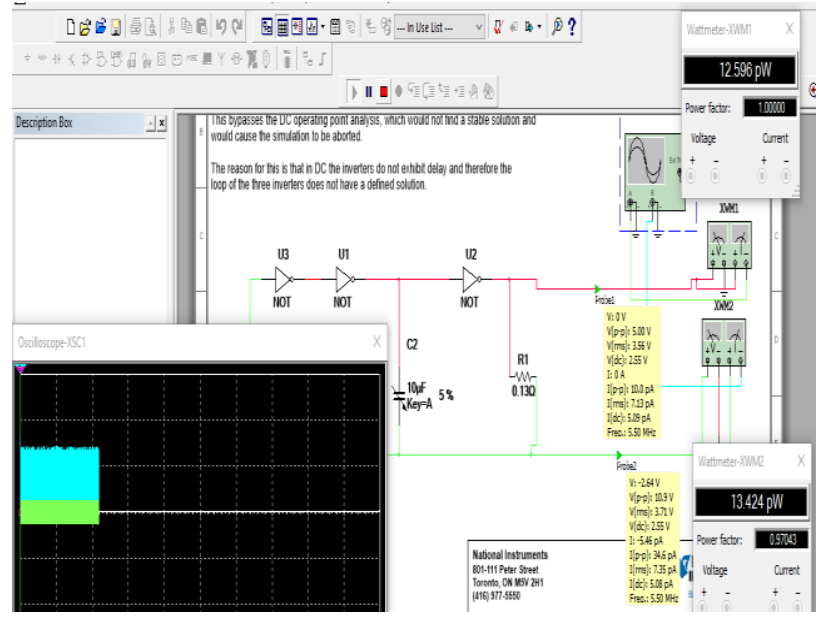

Fig 2: Collpitt's Oscillator and its Output Waveform

\subsection{RC Oscillator Implementation}

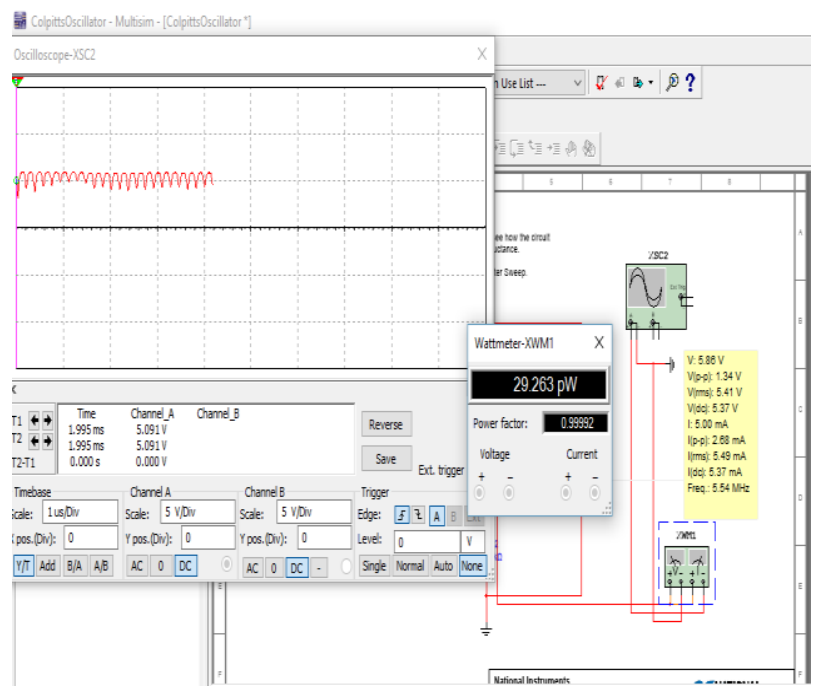

Fig. 3: RC Oscillator

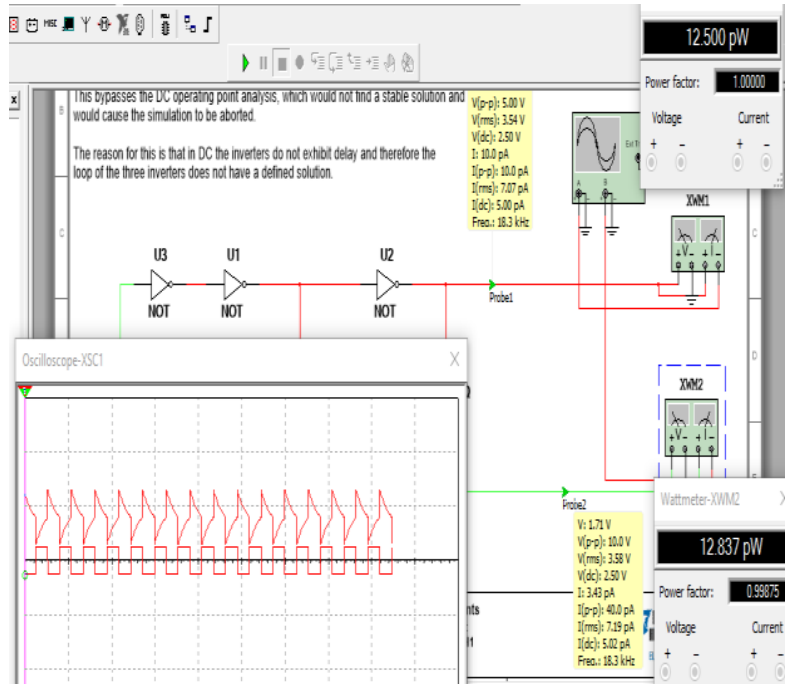

Fig 4: RC Oscillator Output Using Conventional Method

\subsection{Wein Bridge Oscillator}

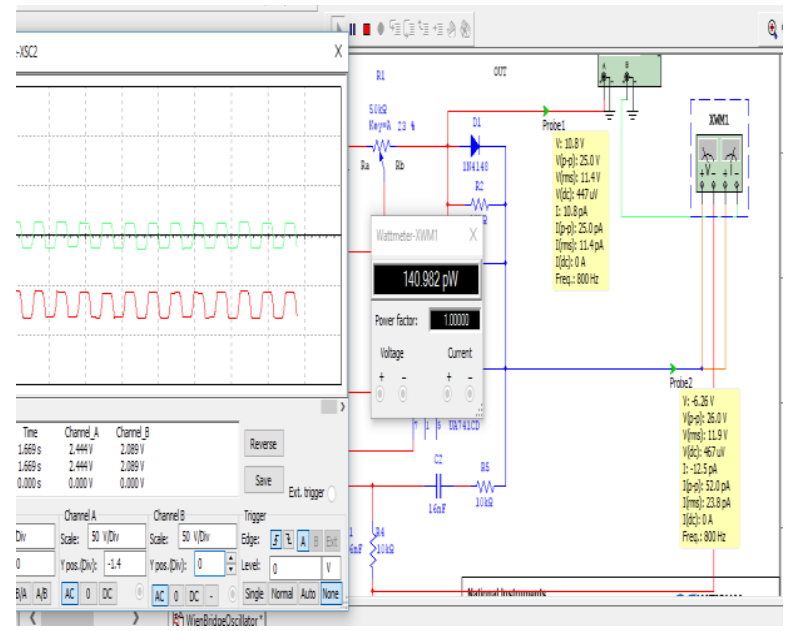

Fig 5: Wein Bridge Oscillator and its Output waveform

\subsection{CCCII based RC Oscillator for generation of $5 \mathrm{MHz}$ frequency}

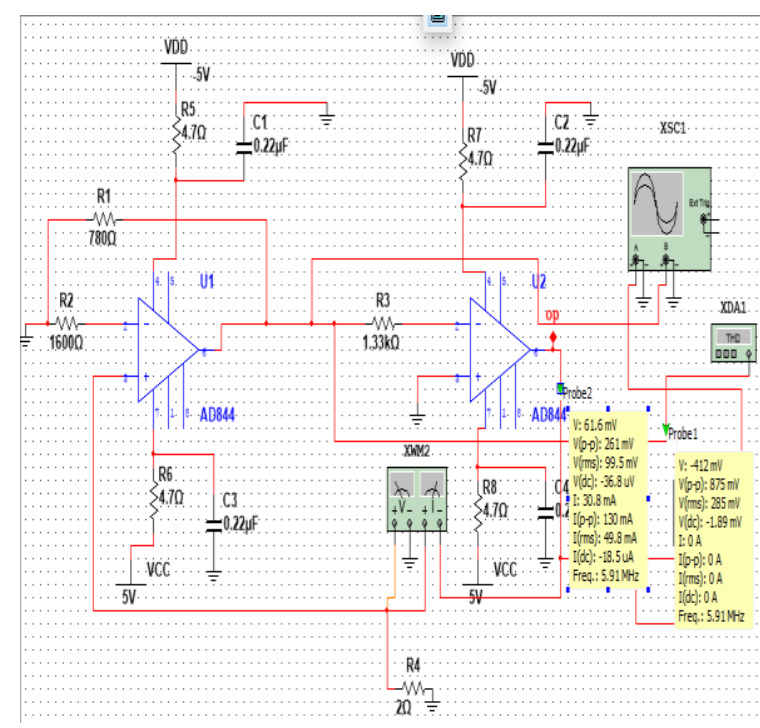

Fig 6: Design of CCII based RC Oscillator 
Output Waveform for CCII based RC Oscillator is shown in Figure 7 below:

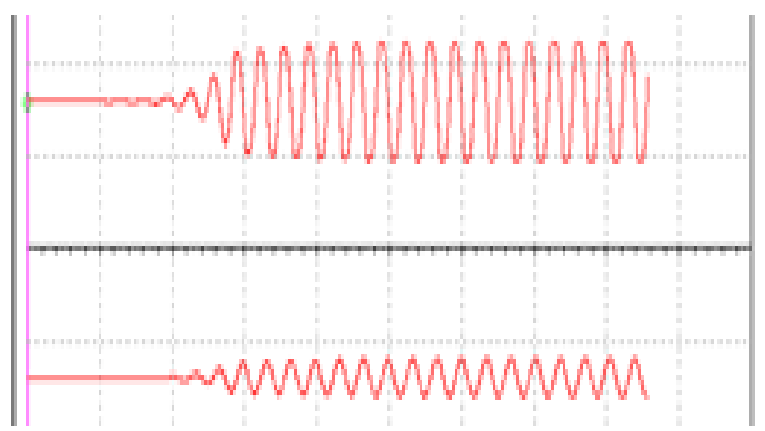

Fig 7: Output of Proposed Oscillator

It is clear from Figure 7 that the proposed oscillator is producing sinusoidal output of $5 \mathrm{MHz}$ and the oscillations this produced are very fine too.

\section{COMPARATIVE ANALYSIS OF MENTIONED OSCILLATORS}

Table 3. Parameter Comparison of Oscillators

\begin{tabular}{|c|c|c|c|c|c|c|c|c|c|c|}
\hline \multirow[b]{2}{*}{$\begin{array}{l}\text { Type of } \\
\text { Oscillator }\end{array}$} & \multicolumn{10}{|c|}{ OP Parameters } \\
\hline & v & $\begin{array}{c}V \\
(p-p)\end{array}$ & $\begin{array}{c}\mathrm{V} \\
\text { (rms) }\end{array}$ & $\begin{array}{c}\mathrm{V} \\
\text { (dc) }\end{array}$ & I & $\begin{array}{c}1 \\
(p-p)\end{array}$ & $\begin{array}{c}1 \\
\text { (rms) }\end{array}$ & $\begin{array}{c}1 \\
\text { (dc) }\end{array}$ & Power & Freq \\
\hline Crystal & $\begin{array}{c}6.07 \\
V\end{array}$ & $14 \mathrm{~V}$ & $5 \mathrm{~V}$ & $\begin{array}{l}614 \\
\text { uV }\end{array}$ & $\begin{array}{c}12.1 \\
\mathrm{pA}\end{array}$ & $\begin{array}{l}28 \\
\mathrm{pA}\end{array}$ & $\begin{array}{l}10 \\
\mathrm{pA}\end{array}$ & $O A$ & $25 \mathrm{pW}$ & $\begin{array}{c}5 \\
\mathrm{MHz} \\
\end{array}$ \\
\hline $\begin{array}{c}\mathrm{RC}(\mathrm{R}=10 \\
\mathrm{Ohms})\end{array}$ & $5 \mathrm{~V}$ & $5 \mathrm{~V}$ & $3.54 \mathrm{~V}$ & $\begin{array}{c}2.5 \\
\mathrm{~V} \\
\end{array}$ & $\begin{array}{l}10 \\
\mathrm{~Pa}\end{array}$ & $\begin{array}{l}10 \\
\mathrm{pA}\end{array}$ & $\begin{array}{l}7.07 \\
\text { pA }\end{array}$ & $5 \mathrm{pA}$ & $\begin{array}{l}12.5 \\
\mathrm{pW}\end{array}$ & $\begin{array}{l}8.3 \\
\mathrm{kHz} \\
\end{array}$ \\
\hline $\begin{array}{c}\mathrm{RC}(\mathrm{R}=75.5 \\
\mathrm{mOhms})\end{array}$ & ov & $5 \mathrm{~V}$ & $3.53 \mathrm{~V}$ & $\begin{array}{c}2.51 \\
\mathrm{~V}\end{array}$ & $\begin{array}{c}0 \\
\mathrm{Am} \\
\end{array}$ & $\begin{array}{l}10 \\
\mathrm{pA}\end{array}$ & $\begin{array}{l}7.07 \\
\mathrm{pA}\end{array}$ & $\begin{array}{c}5.01 \\
\mathrm{pA}\end{array}$ & $\begin{array}{c}12.617 \\
\mathrm{pW}\end{array}$ & \begin{tabular}{|c|}
5.6 \\
$\mathrm{MHz}$ \\
\end{tabular} \\
\hline $\begin{array}{c}\text { Collpits } \\
\text { Oscillator }\end{array}$ & $\begin{array}{c}5.82 \\
\mathrm{~V}\end{array}$ & $\begin{array}{c}2.41 \\
\mathrm{~V}\end{array}$ & $5.4 \mathrm{~V}$ & \begin{tabular}{|c|}
5.37 \\
V \\
\end{tabular} & $\begin{array}{l}5.1 \\
\mathrm{~mA} \\
\end{array}$ & $\begin{array}{c}2.37 \\
\mathrm{~mA} \\
\end{array}$ & $\begin{array}{c}5.51 \\
\mathrm{~mA} \\
\end{array}$ & $\begin{array}{c}5.37 \\
\mathrm{~mA}\end{array}$ & $\begin{array}{c}29.168 \\
\mathrm{pW}\end{array}$ & $\begin{array}{l}5.54 \\
\mathrm{MHz} \\
\end{array}$ \\
\hline $\begin{array}{c}\text { Wein Bridge } \\
\text { Oscillator }\end{array}$ & $13 \mathrm{~V}$ & $26 \mathrm{~V}$ & $11.9 \mathrm{~V}$ & \begin{tabular}{|l|}
231 \\
uV \\
\end{tabular} & $\begin{array}{l}26 \\
\mathrm{pA} \\
\end{array}$ & $\begin{array}{l}52 \\
\mathrm{pA}\end{array}$ & $\begin{array}{c}23.8 \\
\mathrm{pA}\end{array}$ & $O A$ & \begin{tabular}{|c|}
141.22 \\
$3 \mathrm{pW}$ \\
\end{tabular} & \begin{tabular}{|l|}
800 \\
$\mathrm{~Hz}$ \\
\end{tabular} \\
\hline CCII Based & 61.6 & $261 \mathrm{~m}$ & $99.5 \mathrm{~m}$ & 36.8 & 30.8 & 130 & 49.8 & 18.5 & 4.655 & 5.91 \\
\hline RC Oscillator & $\mathrm{mV}$ & V & V & uV & $\mathrm{mA}$ & $\mathrm{mA}$ & $\mathrm{mA}$ & uA & $\mathrm{mW}$ & $\mathrm{MHz}$ \\
\hline
\end{tabular}

From Table 3, it is clear that the performance of RC Oscillator is increased when it is implemented using active element and this frequency can be used by transducers involved in High frequency Focused Ultrasound equipment so as to have more reliable operations during the non invasive surgeries done by HIFU.

\section{CONCLUSION}

The oscillators play a vital role in many applications including the biomedical applications. High frequency oscillators with minimum power requirements can be explored further in the designing of equipments required for focused ultrasound techniques and other high frequency applications. Being designed by active elements, their fabrication on single chip also seems promising.

\section{ACKNOWLEDGMENT}

The timely guidance and moral support provided by my guide Dr. Pragati Kapoor and Dr. Pawan Whig is the key behind the beginning and completion of this paper. Her motivational words were always uplifting my zeal and courage to move ahead. I would also like to extend my heartfelt gratitude to Dr. SVAV Prasad and Dr. Naseem Ahmad whose guidance about transducers and active elements respectively started the inquisitiveness in me to explore this field more and more. My sincere and heartfelt acknowledgment to Mr. Mohan Pandit, Director LMI India Pvt. Ltd. who extended his support for providing the necessary equipments and softwares required for testing these oscillators.

\section{REFERENCES}

[1] Dalibor Biolek, Raj Senani, Viera Biolkova and Zdeněk Kolka, "Active Elements for Analog Signal Processing: Classification, Review and New Proposals", RADIOENGINEERING, December, 2008, Page 17-32, Dec. 2008

[2] Winai Jaikla and Montree Siripruchyanan, "Current Controlled CDTA (CCCDTA)," IEEE, ISCIT, Page 48 351, 2006.

[3] Roman Prokop and Vladisliv Musil, "Building Blocks for Modern Active Components Design", Electronics 2006, Research Gate

[4] Firat Kacar, Abdullah Yesil and Abbas Noori, "New Simple CMOS Realization of Voltage Differencing Buffered Amplifier and Its Biquad Filter Applications", RADIOENGINEERING, Vol. 21, No. 1, 2012, Page 333 $-339$

[5] H.O. Elwan and A.M. Soliman, CMOS Differential Current Conveyors and Applications for Analog VLSI, Analog Integrated Circuits and Signal Processing 11, 1996, Page 35-45.

[6] A. S. Sedra, G. W. Roberts and F. Gohh, "The Current Conveyor: History, Progress and New Results", IEEE Proc. Vol. 137, 1990, Page 78-87.

[7] Abdullah Yesil, Firat Kacar and Hakan Kuntman, "New Simple CMOS Realization of Voltage Differencing Transconductance Amplifier and Its RF Filter Application", RADIOENGINEERING, Vol. 20, No. 3, 2011, Page 632-637

[8] W. Chiu, S.I. Liu, H.W. Tsao and J.J. Chen, "CMOS Differential Difference Current Conveyors and Their Applications", IEEE Proceedings, Vol. 143, 1996, Page 91-96

[9] H.O. Elwan and A.M. Soliman, "Novel CMOS Differential Voltage Current Conveyor and Its Applications", IEEE Proc. 144, 1997, 195-200.

[10] Kasim K. Abdalla, D. R. Bhaskar \& Raj Senani, “A Review of The Evolution of Current-Mode Circuits and Techniques and Various Modern Analog Circuit Building Blocks", Nature and Science, Vol. 10, 2012, Page 1-13

[11] S.A. Mahmoud and A.M. Soliman, "The Differential Difference Operational Floating Amplifier: A New Block for Analog Signal Processing in MOS Technology", IEEE Trans. Circ. Syst. II 45 1998, Page 148-158.

[12] S.I. Liu, H.W. Tsao and J. Wu, "CCII-Based Continuous Time Filters With Reduced Gain Bandwidth Sensitivity", IEEE Proceedings, Vol 138, 1991, Page 210-216.

[13] D. Biolkovád, V. Kolka, and Z, "Universal CurrentMode OTA-C KHN Biquad," International Journal of Electronics Circuits and Systems, Vol.1, 2007, Page 214217, 2007

[14] Soliman A. M, "A New Filter Configuration Using Current Feedback Op-Amp", Microelectronics Journal, 29, 1998, Page 409 - 419 
[15] Nisha Walde and Syed Naseem Ahmad, "New Voltage Mode Sinusoidal Oscillator Using Voltage Differencing Transconductance Amplifiers (VDTAs)", Scientific Research Publishing, Circuits and Systems, Vol. 6, Page $173-178,2015$

[16] E. Vidal, A. Poveda, and E. Alarcon, "Analysis and Design of Active R Oscillators Using The Current Feedback Op-Amp," Proceedings, ECS/IEEE ECCTD, Budapest, Hungary, Aug. 1997, Page 200-203

[17] S. Maiti and R. R. Pal, "Voltage Mode Quadrature Oscillator Employing Single Differential Voltage Current Controlled Conveyor Transconductance Amplifier", International Journal of Electronics and Electrical Engineering, Vol. 3, No. 5, October 2015, Page $344-348$

[18] Firat Kacar, Abdullah Yesil and Hakan Kuntman, "Current - Mode Biquad Filters Employing Single FDCCII", RADIO ENGINEERING, Vol. 21, No. 4, December 2012, Page 1269 - 1278

[19] Zhimin Zhou, Bedaprata Pain \& Erric R Fossum, "CMOS Active Pixel Sensor With On-Chip Successive Approximation Analog-To-Digital Converter", IEEE Transactions on Electron Devices, Vol. 44, Issue 10, Oct. 1997, Page 1759 - 1763

[20] A.M. Soliman, "The Inverting Second Generation Current Conveyors as Universal Building Blocks", Int. J. Electronics (AEU) Vol. 62, Page 114-121, 2008

[21] H. Hakan Kuntman, "New Advances and Possibilities Provided by Alternative Active Elements in Analogue Circuit Design", Electric and Electronic ve Bilgisiyar Sempozyumu, 2011, Page 1-12

[22] Rabindranath Nandi, Sandhya Pattanayak, Palaniandavar Venkateswaran and Sagarika Das,"Electronically Tunable Differential Integrator: Linear Voltage Controlled Quadrature Oscillator", Hindawi Publishing Corporation, Int. Sch. Research Notices, Vol. 2015, Article ID 690923

[23] T. K. Das and S. Chakrabarti, "Design of a Tunable Active Low Pass Filter by CMOS OTA and A Comparative Study with NMOS OTA with Different Current Mirror Loads", International Journal of Electronics and Electrical Engineering, Vol. 3, No. 5, October 2015, Page 377 - 384

[24] Chung-Yu Wu, Chih-Cheng Chen and Jyh-Jer Cho, "A CMOS Transistor-Only 8-b 4.5-Ms/s Pipelined Analogto-Digital Converter Using Fully-Differential CurrentMode Circuit Techniques", IEEE Journal of Solid-State Circuits, Vol. 30, No. 5, May 1995, Page 522 to 532

[25] Chih-Cheng Chen and Chung-Yu Wu, "Design Techniques for 1.5-V Low-Power CMOS Current-Mode Cyclic Analog-to-Digital Converters", IEEE Transactions on Circuits and Systems-II: Analog and Digital Signal Processing, Vol. 45, No. 1, January 1998, Page 28-40

[26] Atsushi Iwata, Noboru Sakimura, Makoto Nagata, and Takashi Morie, "The Architecture of Delta Sigma Analog-to-Digital Converters Using a Voltage-
Controlled Oscillator as a Multi-Bit Quantizer", IEEE Transactions on Circuits and SystemsII: Analog and Digital Signal Processing, Vol. 46, No. 7, July 1999, Page 941-945

[27] Soundarapandian Karthikeyan, Siamak Mortezapour, Anilkumar Tammineedi, and Edward K. F. Lee, "LowVoltage Analog Circuit Design Based on Biased Inverting Opamp Configuration", IEEE Transactions on Circuits and Systems-II: Analog and Digital Signal Processing, Vol. 47, No. 3, March 2000, Page 176-184

[28] Yves Geerts, Michel S. J. Steyaert and Willy Sansen, "A High Performance Multi-Bit $\Delta \sum$ CMOS ADC", IEEE Journal of Solid-State Circuits, Vol 35, No. 12, December 2000, Page 1829-1840

[29] Kush Gulati and Hae-Seung Lee, "A Low-Power Reconfigurable Analog-to-Digital Converter", IEEE Journal of Solid-State Circuits, Vol. 36, No. 12, December 2001, Page 1900-1911

[30] Yu-Yee Liow and Chung-Yu Wu, "The Design of HighSpeed Pipelined Analog to Digital Converters Using Voltage-Mode Sampling and Current-Mode Processing Techniques", Circuits and Systems, ISCAS 2002, IEEE International Symposium, 2002, Page 117-120

[31] S. Chuenarom, S. Maitreechit, P. Roengruen and V. Tipsuwampron, "Low Power Current - Mode Algorithmic ADC in Half Flash (BCD)", Circuits and Systems, APCCAS 2006, IEEE Asia Pacific Conference, 2006, Page 175-178

[32] Atilla Uygur and Hakan Kuntman, "Seventh-Order Elliptic Video Filter With $0.1 \mathrm{Db}$ Pass Band Ripple Employing CMOS CDTAs", International Journal of Electronics and Communications (AEÜ), Vol. 61, 2007, Page 320-328

[33] N. Yoshii, K. Mizutani and Y. Sugimoto , "A Currentmode ADC with Current Exchanging and Averaging Capabilities by Switching the Currents and Calculating Data in the Digital Domain", IEEE 2007 Custom Integrated Circuits Conference (CICC), September 2007, Page 209-212

[34] Veepsa Bhatia, Neeta Pandey and Asok Bhattacharyya, "A 4-bit Expandable Algorithmic Current Mode Analog to Digital Converter for use in Digital Control Systems", Power Electronics (IICPE), 2010 India International Conference, Page 1-4

[35] Md. Kareemoddin, A. Ashok Kumar, Dr. Syed Musthak Ahmed, "Design of Low Power Comparator for SAR ADC in Biomedical Applications", International Journal of Innovative Research in Computer and Communication Engineering, Vol 1, No. 5, July 2013, Page 1161-1167

[36] Rudolf Ritter, Matthias Lorenz, and Maurits Ortmanns, "Anti-Aliasing Filter Improvement in Continuous-Time Feedback Sigma-Delta Modulators", Circuits and Systems (ISCAS), 2015 IEEE International Symposium, 2015, Page 325-328

[37] Focused Ultrasound Foundation www.fusfoundation.org 